\title{
LA FUERZA DEMOCRÁTICA DE LA LUCHA ESTUDIANTIL
}

Francisco Figueroa Cerda y Gabriel Boric Font 


\section{FRANCISCO FIGUEROA CERDA}

Periodista y Licenciado en Comunicación Social de la Universidad de Chile. En 2008 presidió el Centro de Estudiantes de Comunicación (CECO) de nuestra casa de estudios y en 2010 y 2011 fue vicepresidente de la Federación de Estudiantes de la Universidad de Chile (FECH). Pertenece al movimiento Izquierda Autónoma. Fue candidato a diputado en las elecciones de 2013 por el distrito de Nuñoa y Providencia. Es autor del libro Llegamos para quedarnos. Crónicas de la revuelta estudiantil. Hoy se desempeña como director de la Fundación Nodo XXI.

\section{GABRIEL BORIC FONT}

Egresado de Derecho de la Universidad de Chile. En 2009 fue Presidente del Centro de Estudiantes de Derecho (CED) de nuestra Universidad, entre 2010 y 2011 Senador Universitario y en 2012 Presidente de la Federación de Estudiantes de la Universidad de Chile (FECH). Participa en el movimiento Izquierda Autónoma. En 2014 fue electo, como independiente, Diputado de la República por la Región de Magallanes. 


\section{LA FUERZA DEMOCRÁTICA DE LA LUCHA ESTUDIANTIL}

Durante la última década, la sociedad chilena ha sido continuamente sacudida por la movilización de sus estudiantes. Primero fue la llamada "revolución pingüina" en 2006, luego la poderosa revuelta de 2011 y en los años posteriores el sostenido esfuerzo de universitarios y secundarios por cosechar los frutos de esos años de movilización. Se trata de todo un ciclo de luchas, con fines y características propios, cualitativamente distinto de los anteriores y de un impacto político considerable aunque todavía en juego. Como toda experiencia de lucha social, su desarrollo ha sido y seguirá siendo sinuoso e impredecible. Ha tenido momentos de alta conflictividad y otros de reflujo, explosiones y espasmos que se suceden con la regularidad propia de la naturaleza de los movimientos sociales. Con todo, las movilizaciones estudiantiles de la última década han terminado por constituir un hito en la historia del Chile reciente. Uno que notifica sin disimulos la agonía del ciclo político de la transición y, a la vez, anuncia la puja por la apertura de uno distinto.

No es fácil discernir entre lo que es pasajero y aquello que es trascendente en la lucha de movimientos como el estudiantil. En su despliegue confluyen infinidad de aspiraciones de distintos grupos sociales, unos en retirada, otros en formación, no siempre con armonía y muchas veces confrontados. Aunque con variables grados de fuerza y confianza, apela siempre al Estado, uno que, a la inversa, ni siquiera lo valida como un actor ni a sus intereses como legítimos. Su conducción está en disputa permanente entre diversos esfuerzos políticos, la mayoría de izquierda, lo que en realidad no aclara nada en tiempos de tan marcado naufragio político de la izquierda. Y su composición es exclusivamente juvenil, algo obvio pero-quizá por lo mismo- muchas veces mirado en menos. Es decir, es un movimiento generacional. Y vaya de qué generación: una de jóvenes profundamente conflictuados con los valores y horizontes ofrecidos por el orden social vigente y, por lo mismo, resistidos por el régimen.

Como otra de las grandes dificultades para comprender su significado histórico, a su variopinta fisonomía social y política se suma la pobreza de las lecturas interpretativas en boga. A un lado de la corte neoliberal los intelectuales de derecha, en lo que juran un arranque de novedosa creatividad, se apuran en calificar al movimiento estudiantil (y, en general, a cualquier actor que represente intereses no empresariales) como un mero grupo corporativo de presión con altas 
dosis de irracionalidad. Mientras que del otro lado de la misma corte neoliberal, los intelectuales del autodenominado progresismo elaboran intrincados discursos pseudosociológicos para procesar el reclamo estudiantil en términos aceptables para el "neoliberalismo corregido" que propugnan, desechando su contenido político y legitimando su desarticulación y exclusión de las decisiones. El problema de estas lecturas no es que sean interesadas (la que motiva estas líneas también lo es en un sentido distinto), sino la intencionalidad política con que son diseñadas y difundidas: lo que las anima es combatir el ímpetu transformador contenido en la lucha estudiantil para domesticarlo.

¿Cuál ha sido, entonces, el sentido político de la lucha estudiantil de la última década? ¿Cuánto de pasajero y cuánto de trascendente hay en su despliegue? ¿Cobija alguna posibilidad de contribuir a la emergencia de una nueva política? El propósito de estas líneas es indagar en respuestas posibles para estas preguntas, ofreciendo una mirada que permita advertir cuánto de futuro hay en la radical crítica del presente que ha formulado la lucha estudiantil. Pensamos que relacionando la amplitud social de su reclamo, el contenido ideológico de sus demandas y el sentido político de sus pasos, sin limitarse a observar cada dimensión por separado, es que asoma lo esencial de su significado. El valor de la lucha estudiantil radica en la naturaleza democrática de su impulso histórico, en el hecho de que su perspectiva es la superación del privatizado orden actual por la vía de conquistar una plena soberanía de la democracia sobre nuestras vidas.

\section{DENTRO Y EN CONTRA DEL NEOLIBERALISMO}

El movimiento estudiantil ha jugado un papel relevante en la vida política chilena desde comienzos del siglo XX. Su aparición tuvo lugar bajo el contexto de crisis del Estado oligárquico, como vehículo de expresión de las nuevas fuerzas sociales y políticas que emergían en conflicto con el orden imperante. Los elementos más avanzados de las nacientes clases medias se organizaban en torno a sus demandas e instituciones, pujando por derrocar el exclusivismo que ostentaban las oligarquías sobre las riendas de la sociedad. En estos años destacaron la fundación de la FECH, en 1906, y las revueltas de comienzos de los años veinte. Era un movimiento que afirmaba la condición nacional, en oposición a la servil relación de las clases dominantes con el capital extranjero; que acogía y desarrollaba las avanzadas ideas del socialismo, el anarquismo y el cristianismo de izquierda, para oponerlas al pensamiento conservador y a las imposturas del liberalismo; y que luchaba por una educación liberada de las ataduras del clericalismo y alineada con las tareas modernizadoras. 
En la década de 1960, un movimiento estudiantil ahora mucho más imbricado con el sistema de partidos volvió a reclamar protagonismo. La unidad de las clases dominantes se fracturaba, mientras la de los sectores populares aumentaba y se proyectaba políticamente. A ese proceso de radicalización política el movimiento estudiantil contribuyó significativamente, en especial a través de su lucha por la apertura de la universidad en su acceso, enseñanza y producción de conocimiento al cambio social en curso. El golpe militar de 1973 terminó con este ciclo, pero la lucha estudiantil resurgió con fuerza en los ochenta, en el marco de los esfuerzos por acabar con la dictadura, apuntando a reconstruir la educación pública y recuperar la democracia.

Durante el periodo nacional-popular, el movimiento estudiantil estuvo compuesto por los estudiantes de los liceos públicos más importantes del país y por los estudiantes de las principales universidades, a saber, las universidades de Chile, Católica de Chile, Técnica del Estado y de Concepción. Dicho movimiento expresó los deseos de las clases medias por incidir en el curso de la política nacional, así como la búsqueda de la juventud más ilustrada por ampliar los estrechos horizontes de realización personal y colectiva impuestos a la sociedad chilena. En términos de su relación con el Estado, se movió entre la apelación por la inclusión de sus demandas en la institucionalidad y el reclamo por la transformación general de la sociedad, combinando el pragmatismo propio de un sector social con carencias y esperanzas concretas con la vocación de separarse de una condición social específica para reclamar representación del interés social general.

Las transformaciones emprendidas por la dictadura militar cambiaron profundamente la fisonomía de la sociedad chilena y con ella las bases y el carácter de lo que en adelante sería el movimiento estudiantil. De partida la educación dejó de ser concebida como un ámbito de responsabilidad colectiva cuya entrega le correspondía, en tanto derecho de los ciudadanos, al Estado. Desde los ochenta y hasta nuestros días la educación es comprendida como un ámbito de responsabilidad individual al cual son las personas las que, por sus medios, se deben procurar acceso. Lo que está en la base de esta mutación es el paso al Estado subsidiario, una forma de Estado que deja en manos del mercado la provisión de los servicios públicos, apareciendo sólo allí donde a los empresarios no les resulta atractivo, desde una perspectiva de negocios, ingresar. Este giro significó una forma radicalmente nueva de relación entre las personas y su educación. Desde entonces el acceso a la educación está mediado por la capacidad de pago y la expansión de las instituciones educacionales, tanto en el nivel escolar como el superior, dominada por actores privados.

Si bien este giro se inició en la década de 1980, la lucha estudiantil de los noventa no estuvo marcada de modo predominante por una resistencia a la progresiva 
privatización de la educación. Las huellas del autoritarismo estaban todavía demasiado frescas en liceos y universidades, y la Concertación había decidido excluir de las preocupaciones posibles del Estado las aspiraciones de todos aquellos actores sociales que pudieran alterar la entonces celebrada "gobernabilidad democrática". De ahí que en los noventa los estudiantes lucharan por conquistar condiciones mínimas para organizarse y estudiar, lo que significó concentrar su acción en la reconstrucción de federaciones y en la exigencia de una educación más subsidiada. No asomaba todavía una crítica masiva a la privatización misma de la educación. Esa bandera de lucha tendría que esperar por mejores condiciones para ser ondeada.

En los años 2000 el carácter de la lucha estudiantil comienza a mutar. En el 2001 se desarrolla la primera movilización de masas protagonizada por los estudiantes secundarios desde la vuelta de los gobiernos civiles. Se conoció como "el mochilazo" y consistió en la lucha por el derecho de los estudiantes al transporte público, gratuito y garantizado por el Estado. En esos años el pase para los escolares era administrado por los empresarios microbuseros. En el proceso, las propias organizaciones de los estudiantes secundarios se transformaron. Atrás quedaron las burocratizadas federaciones manejadas por las juventudes de los partidos y en su lugar surgió una modalidad de participación más directa en la que nuevas identidades políticas se abrieron paso. En 2005 fue el turno de los universitarios. La lucha contra el déficit estructural de los créditos universitarios dio paso a una resistencia frontal al intento del gobierno por entregar a los bancos la totalidad de las deudas universitarias y el manejo de los créditos.

Con la consolidación del mercado en la educación, lo que también llega es una nueva experiencia para millones de jóvenes en todos los liceos, centros técnicos y universidades del país. Estudiar no es ya una actividad ligada en lo fundamental a la apropiación de conocimientos y habilidades para contribuir, a través de un oficio o profesión, a la sociedad, sino una continua lucha por maximizar las oportunidades de retorno económico privado a futuro. La estructura educacional y los valores promovidos a través de ella forman a los jóvenes en la idea de que estudiar es una "inversión". Su eficacia, sin embargo, no radica en la fuerza de la idea, sino en el mucho más concreto y agresivo abandono de los sujetos a la necesidad de solventar el acceso a la educación con sus propios medios. De este modo, la educación como carrera por un mejor salario a futuro se instala no como fruto de consenso social alguno, sino como imperativo fáctico ante la subordinación de hecho de la posibilidad de educarse a la posibilidad de pagar por ello. Endeudarse por estudiar y estudiar para endeudarse.

Esta experiencia, por supuesto, no nos es presentada como lo que es. Durante la transición, los políticos y tecnócratas impulsores de la mercantilización de la educación la presentaron como un proceso de modernización para el aumento 
de la "calidad" y la "equidad". Se les dijo a los padres de los nuevos estudiantes que si bien el bienestar no estaba asegurado para ellos, sí lo estaba para sus hijos, siempre y cuando estuvieran dispuestos a esforzarse (léase, a pagar) para lograrlo. Paradójicamente, fueron los propios neoliberales quienes construyeron mediante esta propaganda la ilusión de que acabaríamos con la desigualdad a través de la educación. No es que mintieran, lo que se guardaron es que lo que combatían no era en realidad la desigualdad, sino la inexistencia de un modo de volverla legítima. Necesitaban un modo de presentar la desigualdad como válida, no como resultado de una competencia injusta, sino como fruto de una competencia justa. Fue así que encontraron en el mérito la forma de hacerlo y construyeron un relato a la medida de la educación neoliberal.

Mientras se ensayaba esta gimnasia discursiva en las alturas de los círculos tecnocráticos, en la sociedad se estaba larvando un extendido malestar con las consecuencias materiales y culturales de la privatización de la educación. Un primer aviso fue la movilización estudiantil, comandada por los secundarios y seguida por los universitarios, del año 2006. Comenzó como una paralización de los liceos públicos demandando mejoras en la enseñanza y en la infraestructura, pero rápidamente avanzó a un reclamo generalizado contra la ilegitimidad de las bases del sistema educacional en su conjunto y por la construcción de uno distinto. Por primera vez aparecieron las demandas de gratuidad, de fin al lucro, se puso en cuestión la Ley Orgánica Constitucional de Enseñanza (LOCE) y cobraron fuerza las reivindicaciones de estudiantes de instituciones superiores privadas.

La lucha estudiantil de 2006 consiguió también un amplio apoyo social y generó un profundo impacto político. Por un breve lapso de tiempo, la política fue forzada a discutir sobre principios y fines y no ya tan sólo sobre medios. Fue así porque la lucha estudiantil puso en discusión no sólo ni principalmente la educación, sino que el eludido y supuestamente resuelto problema de la desigualdad. Develó, además, la incapacidad de la política para representar los intereses de la mayoría y su decidida opción por continuar "protegiendo" la democracia, no ya del cáncer marxista o de las amenazas de los militares, sino que de la propia ciudadanía. La llamada "revolución pingüina" hizo presentes ante el conjunto de la sociedad chilena las deudas democráticas de la transición. Y obtuvo de la política la respuesta correspondiente: un rotundo portazo a las aspiraciones de reformar la educación.

La génesis de las revueltas de 2011 está en el desenlace de las movilizaciones de 2006. Desde entonces, el movimiento estudiantil ha perseguido como fin la transformación del sistema educacional y, por lo tanto, del Estado. Esta radicalización (en el sentido de ir a la raís) tiene lugar en paralelo al cierre de los partidos y del Estado frente a dicha aspiración, produciendo un marcado distanciamiento entre la movilización social y el sistema político. Esta es la base del carácter del movimiento 
que emerge en 2011. Pero más allá del proceso interno de los estudiantes organizados, es una acumulación de frustraciones en extensos sectores de la sociedad ante los problemas de la educación lo que termina gatillando la revuelta. Lo que resultó decisivo este año fue la inclusión de esos nuevos intereses sociales a través de la movilización de los estudiantes de instituciones privadas de educación superior, cientos de miles de jóvenes abandonados a los bancos y a instituciones con fines de lucro.

Las luchas estudiantiles de la última década cobran así un significado distinto a las de los noventa, porque surgen tanto dentro de como contra el neoliberalismo. En contra, como es evidente, porque se oponen a la educación de mercado y la reclaman un derecho. Y dentro, porque emerge de las propias entrañas de la sociedad que las transformaciones neoliberales impuestas por la dictadura y proyectadas por la Concertación han engendrado. La vieja clase media formada al alero del Estado de compromiso sigue contando con una enorme capacidad de imprimir las señas de identidad más importantes a la lucha estudiantil. Pero esta no habría alcanzado su amplitud ni fuerza sin la participación activa de ese contingente de jóvenes ligados a las dinámicas propias del Chile neoliberal. Y aquí radica la paradoja constitutiva del carácter de la lucha estudiantil actual: son los propios hijos del neoliberalismo los que se han rebelado contra sus promesas.

Gracias a estas movilizaciones sostenidas durante la última década por miles de estudiantes, la mejora profunda de la educación es una necesidad que hoy ningún actor político en Chile puede desconocer. El movimiento estudiantil ha expresado el descontento de amplios sectores con una educación opuesta en sus fines y medios a la sociedad que anhelan para sus hijos. Y ha terminado por hacer de la solución a este problema una impostergable prioridad nacional. Así lo demuestran las agendas del actual gobierno y de los partidos políticos, como también las preocupaciones de diversos poderes fácticos ante la posibilidad de una alteración en el status quo.

Pero concluir esto es concluir poco. El reclamo estudiantil ha terminado por rebasar con creces la crisis educacional para poner en entredicho múltiples dimensiones del orden vigente. Distintos sectores de la población y actores sociales han encontrado una caja de resonancia para sus propias demandas en el camino de cuestionamientos abierto por los estudiantes. Así, la movilización estudiantil de la última década estampa un malestar largamente incubado entre los chilenos ante los problemas derivados de la aguda privatización de sus condiciones de vida: la restricción de sus derechos sociales. 


\section{EL REALISMO DEL RECLAMO ESTUDIANTIL}

El ascenso de la radicalidad y masividad de la lucha estudiantil en los 2000 no habría sido posible sin la concurrencia de un factor propiamente político y externo a la dinámica educacional. Si los estudiantes conquistaron la capacidad de hacerse escuchar por la sociedad, fue en una buena medida porque al mismo tiempo el sistema político la perdió. Conforme se proyectó la desarticulación de los actores sociales y el encierro de los partidos en la pura administración de la burocracia estatal, los partidos perdieron progresivamente la capacidad de mediar entre los intereses sociales excluidos del juego político y el Estado. La defensa naturalizada de la "gobernabilidad" horadó profundamente la capacidad de la política como la conocíamos para relacionarse con la sociedad, dejándola como un espectador cruzado de brazos ante el ascenso del descontento social.

La raíz de este divorcio no es entonces, como suele pensarse, la extrema concentración de poder en manos de los partidos. El drama es más bien el contrario: la creciente impotencia de los partidos frente a los dilemas que genera la dinámica neoliberal. Esta situación se proyectó precisamente porque durante la transición los partidos que controlaban el Estado vivieron en la ilusión de que estaban gobernando. Fascinados con ese sueño, simplemente no vieron venir el malestar en la ciudadanía, ni menos esperaron encontrarse con su propia incapacidad de procesarlo. Lo que el reclamo estudiantil les enrostró en 2006 y 2011 fue lo poco que les quedaba de partidos políticos a los partidos y lo fácilmente manipulables que resultaban por el poder efectivamente dirigente: el económico.

La lucha por el derecho a la educación se asomó así entre las grietas del sistema político, ahondándolas a cada paso. Desnudó su total falta de perspectivas demostrando lo que no era tanto consecuencia de la movilización como su origen: una crisis de representación que cruza todo el espectro político. Poco tiene que ver la lucha estudiantil con un rechazo ontológico a la política. La exigencia a la política de que juegue el papel que se supone debe jugar en un Estado democrático supone juzgar dicho papel como deseable, o al menos, preferible al que desempeña actualmente. La crítica estudiantil a la política es al mismo tiempo una afirmación de la política. No solo de una política "distinta", lo que es obvio. Antes incluso que eso, es la demanda de una política capaz de mediar intereses, de procesarlos estatalmente, de una política "mínima".

Si la política de la transición se mantuvo dócilmente sumida en este sueño, fue también porque no imaginaba ninguna amenaza a su poder. La irrupción estudiantil tomó por sorpresa a los partidos por la simple razón de que no la concebían posible. A diferencia de la derecha conservadora, en cuya imaginación defensiva todavía pervive la posibilidad de una conspiración izquierdista disfrazada de movimiento 
social, la derecha neoliberal y la Concertación, en el fondo, comparten la idea de que la época en que intereses colectivos subalternos podían organizarse y movilizarse quedó atrás. Para ellos, el siglo XXI es el arribo de una suerte de presente perpetuo en que la puja por una sociedad distinta simplemente desapareció, quedando en su reemplazo sólo luchas particulares y corporativas.

Esta idea, en el caso de la Concertación, es en buena parte una deuda que mantienen con el pensamiento conservador importado por intelectuales de la transición como José Joaquín Brunner y Eugenio Tironi. Formados en el MAPU, pasaron de la ortodoxia marxista más fanática en los setenta a la celebración más entusiasta del neoliberalismo en los ochenta. Para ello, teorizaron lo que fue producto de la reestructuración neoliberal, la represión militar y la desarticulación concertacionista: el declive de las antiguas fuerzas sociales del siglo XX como producto "natural" de la irreversible "modernización" en curso. Fue por esos días que Brunner, aplicando esta lectura a la interpretación de las movilizaciones estudiantiles, sentenció: "Si movimiento estudiantil significa un fenómeno de masas juveniles relativamente homogéneas, que se identifican por oposiciones y alianzas relativamente estables, y que buscan incidir en la marcha de la institución universitaria para convertir a ésta en una partera de la modernidad, entonces diremos que ese movimiento estudiantil ha desaparecido y que no volverá".

La ingenuidad de esta versión criolla del "fin de la historia" no apareció como tal durante mucho tiempo. Desde los ochenta y hasta bien entrados los 2000, goza de una incontestada popularidad entre los círculos de la intelectualidad progresista e influencia en la política de la Concertación. El sentido común de la autodenominada centro-izquierda sigue dominado por la idea de que la sociedad está sumida en una irreversible apatía, cuya única posible expresión es el hartazgo individual y la acción corporativa egoísta. Se trata de una doctrina profundamente cínica, pues elige simplemente desconocer el hecho de que las propias dinámicas sociales engendradas por el neoliberalismo fuerzan a la fragmentación social y validan como legítima únicamente la motivación individual. Para que la crítica a la fragmentación no sea una impostura primero hay que proponerse combatirla.

No madura todavía en el debate una respuesta que, además de consistente intelectualmente, tenga la fuerza política para oponerse a esta mirada. Han tenido que ser un diverso abanico de movilizaciones sociales, entre las cuales la estudiantil asoma sólo como la más articulada y potente, pero no la única, las que contradigan

6 Brunner, José Joaquín (1985): "El movimiento estudiantil ha muerto. Nacen los movimientos estudiantiles”. Material de discusión, Número 71, FLACSO, Santiago de Chile. Pág. 19. En: www.cronopio.flacso.cl [Consultado en 01-02-13] 
esta ilusión por la vía de los hechos. La irrupción estudiantil de los últimos años, en este sentido, ha desempeñado un papel desmitificador poderoso y fundamental para la posibilidad de imaginar una política distinta, basada en la organización y proyección de esos intereses excluidos a la construcción del Estado.

Pero el papel desmitificador del movimiento estudiantil está lejos de acabarse aquí. La crítica a la impotencia de la política y la demostración de la existencia de fuerzas colectivas es tan sólo su punto de partida. Así como la política de la transición se ha dormido en el mito del fin de la movilización popular, ha descansado con igual confianza en la supuesta inevitabilidad de la mejora del neoliberalismo. En un retorno a la época en que las elites confiaron ciegamente en las bondades interminables del progreso por la vía del capitalismo de laissez faire (que produjo las contradicciones que engendraron las guerras más cruentas en la historia de la especie humana), los políticos de la transición, en todas sus versiones, postulan que sigue siendo posible conciliar el actual modo de desarrollo con los anhelos de igualdad y libertad a través de la regulación del neoliberalismo. Esta es la convicción que ha estado en la base de las políticas públicas de los últimos 40 años en Chile.

En el caso de la educación, todas las políticas estatales han estado inspiradas en esta utopía. Para los sucesivos gobiernos de la transición, el modo de combatir los estragos producidos por el mercado educacional ha sido intentar regularlos. Todos estos esfuerzos han fracasado. Se permitió la privatización de las universidades y se quiso evitar que lucraran creando una ley. Pero los empresarios de la educación superior encontraron la forma de lucrar de todos modos. Se optó por prescindir de un modo público de garantizar la buena y pertinente enseñanza y producción de conocimiento, limitando al Estado como acreditador de una "calidad" determinada por los particulares. Pero los empresarios de la educación encontraron el modo de comprar las acreditaciones. Se pretendió "racionalizar" las políticas de financiamiento a través de las subvenciones en aras de fortalecer la condición "mixta" de la educación. Pero terminaron precarizando la educación pública y, tampoco mejorando la privada, sino que siendo base de nuevos negocios asociados a la educación. Se quiso disminuir el costo de los estudios para las familias y para el Estado por la vía de incorporar a los bancos a la provisión de créditos. Pero resultó en mayores deudas para los estudiantes, cuantiosas pérdidas para el Estado y en un jugoso negocio para los bancos.

Ante estos sucesivos fracasos del intento por construir una educación a imagen y semejanza de un "neoliberalismo con rostro humano", los estudiantes han dicho algo mucho más simple y liberado del utopismo de los políticos neoliberales: no se puede tener una educación buena y justa si la entregamos al mercado. El interés de la sociedad en una educación que sirva a sus fines es simplemente inconciliable con el interés de los particulares por hacer de ella una oportunidad de negocio. De 
ahí que, por lo tanto, todo intento por equilibrar la balanza redunde en un nuevo modo en que los empresarios encuentran la vía para desequilibrarla a su favor. En esto consiste lo central de la crítica del movimiento estudiantil a los defensores de la educación de mercado. Es un nuevo capítulo de la vieja lucha entre realismo e idealismo en política.

El dilema en el que está entrampado el actual gobierno ante el desafío de implementar una reforma educacional sigue siendo ese. Desde 2011 hasta la fecha, el movimiento estudiantil no sólo ha mantenido el realismo de su planteamiento, sino que incluso lo ha profundizado. Esto es patente en lo mucho más detallado y concreto que es el debate educacional que el sostenido hace un par de años, cuando la conversación todavía giraba en torno a las grandes consignas de la gratuidad, el fin del lucro y la educación pública. Sin embargo, lo que también se mantiene inalterado es la confianza de los actuales responsables de la política educacional del gobierno de la Concertación en las bondades de la regulación del mercado educativo. El idealismo de los tecnócratas, su deificación de los mecanismos de regulación y fiscalización de la acción de los privados, en definitiva, su deificación del Estado neoliberal, sigue entrampando la posibilidad de una genuina reforma a la educación.

Decir que contener la voracidad del mercado regulándolo es imposible, no equivale a decir que la desmercantilización de la educación sea un desafío fácil. Pero tampoco se puede eludir ese desafío alegando que el movimiento estudiantil no ofrece un modo de hacerlo posible. No se puede porque no es responsabilidad de los estudiantes hacerlo, como tampoco es posible que un movimiento social formule políticas públicas específicas para realizar los planteamientos que demanda. Este discurso, muy de moda entre los partidarios del actual gobierno, no es más que un modo de eludir las responsabilidades que le caben a la política en el desafío de implementar los cambios necesarios.

La fuerza desmitificadora de la lucha estudiantil reciente ya ha hecho bastante en la tarea de contribuir a una superación de la crisis educacional. En su esfuerzo por derrumbar los mitos en torno a la política, los movimientos sociales y la educación, terminó por desnaturalizar las opciones políticas tomadas durante la transición. Dichas opciones se presentaron al país como las únicas posibles y se validaron por la vía de negar derecho a opinión a todo el que no ostentara la condición de experto. Esta actualización del autoritarismo excluyó de las decisiones a las miradas más realistas y críticas de lo obrado, dejando las políticas educacionales (y también las relativas a la salud, la previsión y un sinfín de áreas) en manos de tecnócratas de un idealismo exacerbado y sutilmente autoritario. Hoy, al menos, esta situación puede ser reconocida como tal y debatida abiertamente. Las fronteras del debate fueron ampliadas. 
En paralelo a su papel desmitificador, el movimiento estudiantil de los últimos años también ha formulado una respuesta a la crisis de la educación. No un programa detallado, por cierto. Se equivocan quienes esperan de un movimiento social papers académicos y proyectos de ley. Pero sí un horizonte y ciertos principios. $\mathrm{Al}$ fracaso de la política subsidiaria en la educación, el movimiento estudiantil ha opuesto el paradigma de la universalidad de los derechos. Plantea que allí donde hoy hay un Estado que focaliza su acción sólo donde al mercado le interesa, mañana haya uno que garantice la educación como un derecho de todos, sólo por el hecho de habitar en Chile. Se concibe esto como vital para la inclusión social, la producción de conocimiento para el desarrollo y la formación de ciudadanía. Ese es el contenido actual de la demanda por educación pública. Es una demanda en la que subyace la perspectiva de un nuevo tipo de ciudadanía y un nuevo tipo de Estado. Una ciudadanía y un Estado fundados ya no en la subordinación al mercado, sino en una ampliación de la democracia.

\section{EDUCACIÓN PÚBLICA Y DEMOCRACIA}

Bien se podría decir que las demandas del movimiento estudiantil no son gran cosa. Mal que mal, aspirar a una educación a la que puedan acceder todos y con la que no se haga negocio es una cuestión que la gran mayoría de las personas considera básica. Más allá de los empresarios de la educación, sin más convicciones que el sonido de las monedas en sus bolsillos, y del puñado de intelectuales devotos de las privatizaciones, las personas comulgan con la idea de que la educación debe ser un derecho. Esto no nos habla de que por ser ampliamente deseado, el derecho a la educación sea una realidad que tengamos a la vuelta de la esquina. No sólo no se ve como algo posible en el corto plazo, sino que todo indica que para realizarse se necesita una radical transformación política. Pero sí nos habla de que la acusación de maximalismo que se hace sobre el movimiento estudiantil no tiene ningún asidero. Por el contrario, lo que esta realidad demuestra es lo extrema que se ha vuelto la defensa del neoliberalismo.

Ante este extremismo neoliberal, el movimiento estudiantil ha planteado algo muy simple: un Estado subsidiario mejorado y más regulación pública no implica necesariamente menos mercado. Esto, porque en esa idea persiste la reducción de lo público a los subsidios y a las regulaciones de los privados y de lo estatal como un equivalente al privado. Sostener que sobre la base de estos principios es posible construir un mejor sistema educacional es equivocado. Esta concepción ya tuvo 30 años para hacerse cargo y el resultado ha sido una educación altamente segregada, de pobre contribución en términos de conocimiento y estrechamente concebida 
como entrega de habilidades instrumentales. Simplemente, no tiene nada nuevo que ofrecerle a Chile.

Contra la reincidencia en las fracasadas fórmulas neoliberales, la lucha estudiantil ha levantado a la educación pública como centralidad de una reforma progresiva. A diferencia de lo que usualmente se piensa, no siempre la educación pública ha estado en la primera línea de preocupaciones del movimiento estudiantil. Lo estuvo en los años veinte, como alternativa a la educación confesional defendida por la Iglesia y el conservadurismo. Lo estuvo en los años ochenta, como defensa del modelo educacional del ciclo nacional-popular conquistado durante décadas por las fuerzas de avanzada. Y lo está hoy, pero de modo distinto. No es una defensa del viejo sistema educacional del siglo XX. Tampoco una mera negación de la educación privada o religiosa. Responde a las carencias y desafíos propios de la época actual.

La demanda por educación pública, o más bien, por una nueva educación pública, expresa el contenido democrático de la lucha estudiantil antineoliberal. Y lo hace desde una concepción sustantiva de la democracia que se diferencia de la vacía concepción propia de la democracia existente. Lo que se propone la educación pública es hacer realidad, al menos en el ámbito educacional, el principio de igualdad y de ciudadanía. En lugar de reducir la igualdad al ámbito de la participación formal e individual en la esfera estatal, presupone el desafío de crear condiciones reales para la ampliación de los considerados "iguales" y asume la tarea de otorgar herramientas para el ejercicio de esa igualdad, esto es, para la ciudadanía. Esta orientación, que a primera vista puede parecer tan simple, es radical bajo el neoliberalismo. Implica desmercantilizar. Y se propone recuperar soberanía de los ciudadanos sobre la determinación del rumbo que toma la sociedad.

Es aquí donde radica aquello que, en última instancia, vale la pena rescatar del espíritu de la lucha estudiantil antineoliberal. Que es lucha por democracia social y por democracia política. He allí el elemento que debe ser recogido y proyectado, pues interpretando las contradicciones de nuestra época, discrimina entre aquello que está agotado y aquellos valores progresivos a cuyos contenidos urge darles una perspectiva política. Ya no se trata de un desafío cuya responsabilidad resida en el movimiento estudiantil. Se trata de un objetivo que debe ser asumido con plena conciencia y responsabilidad por las fuerzas políticas de cambio, pero también por quienes detentan poder en la conducción de las instituciones más relevantes de la sociedad civil, como las universidades públicas.

Educación pública es democracia social porque supone democratizar el acceso, los usos y la producción de aquello que es cada día más fundamental para la igualación de las relaciones sociales: el conocimiento. Hoy, al interior de las sociedades contemporáneas, así como entre sociedades de distintas naciones, la desigualdad se reproduce de modo predominante a través de la progresiva concentración de 
la propiedad del conocimiento y aptitudes avanzadas. A través de la apropiación privada del conocimiento se edifican relaciones de desigualdad y dependencia. El combate a la desigualdad requiere de la democratización del conocimiento.

Pero educación pública es también democracia política. La necesitamos con urgencia por la profunda crisis que atraviesa la democracia, por la desafección ciudadana frente a la política y la desesperanza ante la posibilidad de gobernar lo común en aras del interés de la mayoría. Revitalizar la democracia, entonces, nos demanda tomar un compromiso activo con la formación de ciudadanía. Es una tarea ineludible. ¿Es educación pública simplemente más Estado? No. El neoliberalismo ha privatizado el Estado. Reconstruir y ampliar lo público supone democratizarlo. De ahí la importancia de trabajar por la construcción de una nueva educación pública. Una cuyos fines y medios sean deliberados por la ciudadanía y concebida, por lo tanto, como responsabilidad colectiva.

En democracia, en definitiva, y sobre todo en una tan debilitada como la actual, la educación no puede tener un papel neutral, funcional a la monótona reproducción del status quo. En democracia la educación tiene un deber con la superación de la realidad social. Para la educación aplica hoy con toda plenitud y especial fuerza lo que el socialista y Rector de la Universidad de Chile entre 1963 y 1967, Eugenio González, concebía sobre la universidad: "Es también la universidad -y debería serlo principalmente- una persona moral que toma debida y oportuna conciencia, en cada circunstancia histórica, de las fuerzas renovadoras que aparecen como impulsos ciegos de la voluntad colectiva. Esto significa que la Universidad tiene la obligación de contribuir a orientar el movimiento social hacia objetivos valiosos de convivencia superior. Defendiendo en toda circunstancia y sin claudicaciones las conquistas significadoras de la personalidad humana"7.

Los intereses que se oponen a una reforma educacional democrática son muy poderosos. Sólo una amplia mayoría social y política será capaz de hacerla realidad. La concurrencia de los actores sociales del mundo educacional, y en especial del movimiento estudiantil, en la formulación y defensa de una reforma es fundamental. Lo es en un sentido práctico inmediato: los entendimientos entre los pasillos de la política oficial no bastan, porque ante la presión de los poderes fácticos son más débiles que nunca antes en la transición. Pero lo es también en un sentido más fundamental, porque en la resolución de la crisis educacional no sólo está en juego la educación, sino también la salud de la democracia. Ese es el desafío con que, en última instancia, nos interpela la lucha estudiantil de la última década.

7 Eugenio González Rojas, en discurso pronunciado en ocasión de la inauguración del año académico en la Escuela de Derecho de la Universidad de Chile sede Valparaíso, abril de 1965. 